final examinations and had to be airlifted to the United Kingdom to sit for the London Conjoint Board Examinations.

The dispute is now four months old and there is, at present, little prospect of an equitable solution. The MAM is resisting legislation which has transferred licensing powers from the Medical Council to the Minister of Health in so far as foreign medical graduates are concerned. Though not, in principle, against the introduction of a twoyear preregistration period, the MAM is objecting to the imposition of permanent professional exile as a penalty for those young doctors who fail to serve for two years in Government hospitals immediately after qualification. The MAM is convinced that recruitment of housemen can be achieved by far less drastic and more humane methods.

As things stand, these original issues have become overshadowed by more fundamental considerations involving minority rights in a democracy. The attitude of the Maltese Government towards the medical profession in this dispute is more reminiscent of conditions prevailing in totalitarian states.

Your readers are asked to appreciate that Maltese doctors are currently engaged in a struggle in defence of professional freedom and the rights of minority groups. In this hey deserve not only moral support but also more tangible aid from medical colleagues throughout the world.

\section{J German}

Paceville Honorary Secretary,
Association of Malta

Malta

** Maltese doctors who subscribe to the $B M \mathcal{F}$ are invited to contact the $B M \mathcal{F}$ if they wish to receive the classified advertisement section (normally excluded from overseas editions of the Journal).-ED, BMF.

\section{Children's eye clinics}

SIR,-The recent correspondence on screening for visual defects in children has displayed a wide measure of agreement that it is desirable, and a considerable diversity of views on how or where to do it-all of which have their merits. Perhaps the most controversial point otherwise arising is the school eye clinic, which Dr R M Ingram (1 October, p 890) describes as anachronistic and $\mathrm{Dr} \mathrm{J} \mathrm{H}$ Cameron (10 September, p 701) as a place for purveying glasses. If, as Dr Catherine $\mathrm{S}$ Peckham has shown (8 October, p 958), visual defects arise de novo through childhood, not to mention that many of those arising pre-school continue through childhood, where should older children go to find advice? Anachronism is not necessarily a reason for discarding a system. To have one's own personal general physician is anachronistic and it is only by persistent argument and demand that private medicine as a whole has been prevented from becoming anachronistic.

In my area over $80 \%$ of the children found to have visual defects in school voluntarily attend the children's eye clinic rather than go elsewhere; and out of 82 new patients from school in the first nine months of 197731 were ordered glasses as opposed to 51 who were not. It would not be an absurd claim to state that children's eye clinics are where you should go if you do not want to be saddled with glasses (pace Dr Cameron). Added to this, there is the finding from a nationwide survey ${ }^{1}$ that $22 \%$ of 11-year-old children possessing glasses saw 69 or better without their glasses and that $25 \%$ of 11 -year-olds with glasses were at best casual wearers.

There are worse fates than possessing glasses. One of the expensive ones, both to the NHS and to children and parents who are psychologically vulnerable to suggestions of handicap, is to possess unnecessary glasses. Worse still is to become conditioned to their use, which is easily achieved in childhood. These findings, in my opinion, indicate not the need to close down eye clinics but to continue and develop the study of the visual problems of children and to reassess the criteria on which prescriptions for glasses are based.

Admittedly, there are difficulties in staffing children's eye clinics, but these could be overcome if the resources of all those skilled in eye work were integrated into a children's ey service which would serve the whole infan and school population, whose physical, visual, and educational development is determining their skills and life style as future adults.

P A GARDINER

Guy's Hospital

Peckham, C, and Adams, B, Child Care, Health and Deviclopment, p 93. 1975 .

\section{Screening children for visual defects}

SIR,-I read the continuing correspondence about screening of infants and preschool children with growing interest.

Dr Elizabeth $M$ Davis writes (1 October, p 891) that community medical officers with the co-operation of health visitors are skilled in the detection of infant squints. What a happy position to be in! As an orthoptist have been doing little else at Guy's Hospital for the past 12 years and can still have difficulty differentiating between a true and apparen squint in some children. When the angle is large there is little problem, but if it is a small angle-less than five degrees-it is more difficult, combined with the problem of testing the vision of young children. Dr Davis states that the visual acuity can be accurately assessed by the age of $3 \frac{1}{2}$ with the Sheridar cards and here I would like to take issue with her, for the majority of squints have better angular than linear vision in the squinting eye. This means that their vision may be recorded as $6 / 6$ right and left whereas, had they been old enough to do Snellen's test or had the linear version of the Sheridan-Gardiner test been used, it might have been found to be as bad as $6 / 36,6 / 6$. This situation is a diagnostic feature of squint. Young children and those unable to co-operate with the SheridanGardiner or Stycar letters may be tested with Stycar fixed balls and asked to pick up Smarties and "hundreds and thousands." The best vision that can be demonstrated with the fixed balls is $6 / 18$ and "hundreds and thousands" represent a near visual acuity of reduced $6 / 60$. Not a very high standard. Hence those that meet this standard may in reality fall well short of normal.

I agree with $\mathrm{Mr} \mathrm{R} \mathrm{M}$ Ingram (1 October, p 890) that screening should be organised from the hospital ophthalmic department-he would screen by refraction. Dr Davis has testing visual acuity and diagnosing squint in mind and, while I agree that the child should be viewed as a whole, nevertheless an orthoptist would be the first choice for this part of the screening.

If school eye clinics in their present form were abolished the ophthalmologists doing them would be available to see those who need further investigation and treatment with a better chance of effective treatment at this earlier age without increase in the work load.

W V MULholland

Guy's Hospital
London SE1

SIR,-Dr Robert Ingram's comments (1 October, p 890) on the subject of screening children for visual defects merits the strongest support. For too long has this been a subject where the more screening the better has become accepted dogma, and it is most encouraging to observe a healthy blast of fresh air. His comments on the anachronistic school eye clinics deserve a special support. For too long, in many areas, these have been a bottomless pit into which scarce resources of ophthalmological manpower have been poured, when proper rationalisation of services and division of labour between the already established general ophthalmic services and the hospital eye services would much more appropriately meet the need. Where there is a really efficient non-duplicatory and readily staffed school eye service one would not advocate abolition, but, as, for example, in the South-east Thames Region, where circumstances are far from this case, steps have already been taken to rationalise the system and there has been no detectable deterioration of services.

On visual screening, $\mathrm{Mr}$ Ingram's remarks again are fully apposite. It is essential that the criteria for this are fully established and that an approach is made to achieving standardised methods and equipment, as well as ages of screening, on a national basis so that practices such as the unlit test card at the end of an unlit school corridor, or an automatic visual screener designed for adults, operated by an audiology technician, become things of the past. In conclusion, may one be permitted to underline the very real defects and deficiencies by an anecdote. When I spoke at a course for school eye nurses on the topic of the visual assessment of children, in question time a practising and conscientious school eye nurse commented that I appeared to place a lot of emphasis on the distance of the child away from the test chart. It was her practice to put the little ones nearer a chart to make it easier for them to see! One or two other nurses mentioned that they also did the same thing. This is an important topic and $\mathrm{Mr}$ Ingram's labours do much to show us the way along which we should go.

M J GiLkes

Sussex Eye Hospital, Brighton

\section{Demand for patient care}

SIR,-Di S N Donaldson and others (24 September, p 799) are correct in pointing out that a number of patients in acute hospital beds were receiving an inappropriate level of care-something which is obvious to most clinicians who have responsibility for the care of patients with acute illnesses. This is certainly true for my own specialty, particularly with respect to women. I therefore analysed the female patients currently admitted 